\title{
What direction for AIDS drug task force?
}

The high-profile and high-powered National Task Force on AIDS Drug Development, announced by President Clinton in November 1993, is charged with cutting through bureaucratic red tape to assist in the delivery of effective AIDS drugs to the market. When the task force first convened in April 1994, its eighteen members faced more than just a shortage of promising AIDS drugs. "More bureaucratic smoke and mirrors," jeered representatives of the AIDS activist group ACI-UP/New York, leery of any administration-led initiative. "This task force has been met with a big yawn," said Peter Staley, a task force member and representative of the Treatment Action Group of New York, at the first meeting. "At least we won't be suffering from toohigh expectations." Sixteen months later, even its members are wondering aloud whether the task force is meeting even low expectations, finding itself entangled in the red tape it was supposed to sever.

At the June meeting of the task force, in addition to discussing recommendations both for creating greater industry incentives to develop new AIDS drugs and for ways to accelerate approval of those drugs through the US Food and Drug Administration (FDA) process, the attending members (10 of the 18) discussed the future of the task force itself. Several members, including Harold Varmus, director of the US National Institutes of Health (NIH), suggested that perhaps the task force has "outlived its usefulness". Others expressed the desire to continue, although acknowledging that obstacles to the success of the task force may be more significant than first thought.

The difficulties encountered by the task force in its first two years have been as numerous as those posed by AIDS itself. Chartered by Health and Human Services Secretary Donna Shalala to "identify any barriers that may be preventing the rapid development and evaluation of treatments, and then to identify steps that can be taken to remove such barriers", the task force has found itself at times caught up in political correctness, perceived industrial secretiveness, and bureaucratic requirements.

The red tape problem is the most vexing to several members, especially since the task force was supposed to be im-

mune from Washingtonian 'businessas-usual'. "Unless the task force is restructured so that it is not totally bogged down in the bureaucracy, it isn't worth it," says Ben Cheng of the AIDS activist group Project Inform in San Francisco, and a task force member. One example, cited by Cheng, is the slow progress made in constructing and sending a questionnaire to drug companies to gather information on promising drugs in the pipcline. Although the idea to gather the information was made and accepted by the task force members a year ago, the slow approval process required by the government has apparently stalled the effort. "It is pointless to con-

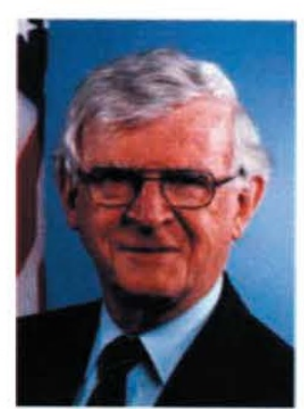

Assistant Secretary for Health Philip Lee, Chair of the National Task Force on AIDS Drug Development. what," said G. Kirk Raab, a task force member and former chief executive officer of Genentech Inc. of South San Francisco (see Did You Know? p. 732) in a written response to questions about the task force's structure. "Although the participants are excellent, in the end the task force is just not designed to recommend meaningful action."

"The task force in its present format should not continue," agrees Art Amman, director of the Ariel Project for the Prevention of HIV Transmission from Mother to Infant. Amman believes that the task force has fulfilled the first part of its mission, successfully identifying the main obstacles to new AIDS drug development, but now must turn its attention to the more difficult second part of its charter, the removal of those obstacles. "We do not need to spend more time identifying issues," he says, "but rather bringing them to conclusion." Amman suggests that the task force should give way to smaller groups, composed of experts in the area assigned to each group. He points out that, to be successful, each group must have direct access to "major decision-makers" like Varmus, Assistant Secretary for Health and task force Chair Philip Lee, and FDA Commissioner David Kessler.

Other members feel the task force should continue in its current form. "We [the task force] have made significant progress," says Stephen Carter, senior vice-president of worldwide clinical research and development at BristolMyers Squibb in Princeton, New Jersey, and one of the task force members representing industrial concerns, "but our work is not finished." Carter cites the pending reforms of the FDA and the NIH's National Cancer Institute as two areas of vital concern to AIDS drug development and thus areas where task force members could offer useful input.

Perhaps the biggest problem the task force has faced is the sheer number of obstacles identified on the long path between the discovery of promising new AIDS drugs and the clinic. This has forced the members to address issues that appear to be tangential to the task force's stated mission. "A good example is the huge amount of time and effort we spent on recommendations to provide women with greater access to clinical trials," said one task force member (who spoke on condition of anonymity). "It's a legitimate concern, but not what the task force should be about."

Although questions about its effectiveness in fulfilling its stated role are being raised by some of its own members, Lee points out that the task force has made several recommendations, now in various stages of approval or implementation, that should ease the way for new AIDS drugs to come to market. These include ways to "ensure adequate resources, improve mechanisms for communication, address problems facing diverse populations, and minimize burdensome regulations," says Lee, who cautions against too-high expectations. "As much of the task force's work has targeted early phases of drug discovery and development, obviously, actions taken in these areas are not expected to bear fruit overnight."

FinTAN R. STEELE 